\title{
A CONSTITUIÇÃO DA SUBJETIVIDADE NO DISCURSO DO IDOSO SOBRE SI
}

\author{
Adélli Bortolon Bazza* \\ Universidade Estadual de Maringá \\ Departamento de Língua Portuguesa \\ Maringá, PR, Brasil
}

\begin{abstract}
Resumo: Neste estudo, propôs-se analisar a subjetivação do idoso em contexto de ensino na Universidade Aberta à Terceira Idade (UNATI) da Universidade Estadual de Maringá (UEM). Enquanto alguns trabalhos abordam o discurso sobre o idoso, propõe-se analisar as práticas que compõem um discurso do idoso sobre si. Embasada em uma perspectiva discursiva, calcada no pensamento de Michel Foucault, objetivou-se descrever o processo de subjetivação do estudante da UNATI-UEM, a partir da oposição sujeição-subjetivação. A série enunciativa analisada foi composta de dez entrevistas semiestruturadas feitas com estudantes da UNATI-UEM e de doze relatos produzidos por eles. A análise apontou que os sujeitos participantes pesquisados estabelecem resistencia ao ideal de novo idoso, na medida em que adotam algumas das práticas que compõem essa subjetividade, enquanto rejeitam outras.
\end{abstract}

Palavras-chave: Subjetividade. Idoso. Discurso.

\section{INTRODUÇÃO}

Neste artigo, propõe-se abordar a constituição da subjetividade de idoso atual, a partir de um olhar discursivo. Dentre uma sociedade multifacetada e composta de inúmeros sujeitos, sejam eles maioria ou minoria social, recorta-se para a discussão a subjetividade do idoso, tendo em vista a representatividade que esse grupo vem ganhando na sociedade.

Pesquisas constataram um aumento da população idosa em alguns países do mundo - em geral, dos países mais desenvolvidos. No Brasil, dados dos censos 2008 e $2010^{1}$ sugerem mudanças na população brasileira: aumenta a proporção de idosos em relação às demais faixas etárias. Esse fenômeno foi chamado de envelhecimento da população e pode ser creditado, entre outras coisas, ao desenvolvimento da medicina e de farmacologia, que garantiram um aumento da expectativa de vida.

O crescimento da quantidade de idosos no país ocasionou um aumento de sua representatividade, que desencadeou inúmeras ações sociais como: a revisão das regras da Previdência Social, a homologação do Estatuto do Idoso, a implementação de

\footnotetext{
*Doutora em Letras (PLE/UEM). E-mail: adellibazza@hotmail.

1 Disponível em: <censo2010.ibge.gov.br/noticias-censo?view=noticia\&id=3\&idnoticia=1722\&busca $=1 \& \mathrm{t}=$ dados-preliminares-censo-2010-ja-revelam-mudancas-piramide-etaria-brasileira $>$. Acesso em: 6 mar. 2016.
} 
programas de atenção ao idoso e à sua saúde, entre outros. Além dessas mudanças, o mercado de consumo passou a desenvolver publicidade específica para essa faixa etária, colocando-a como foco de muitos produtos midiáticos. Diante de todas essas mudanças, as pessoas com mais de sessenta anos se deparam com novas condições de vida, com nova relevância social, com novas formas de viver a velhice e com uma intensa produção discursiva a respeito de sua subjetividade.

Os discursos produzidos sobre os indivíduos pertencentes à chamada terceira idade apresentam certa regularidade que dá visibilidade ao trabalho de (re)construção da subjetividade desse grupo, que passa a receber o nome de "novo idoso". Esse processo discursivo opera uma espécie de classificação desse sujeito. Ao se descrever quem ele supostamente é, apresentam-se as práticas que se espera que ele assuma para ocupar o lugar de novo idoso na sociedade contemporânea. Diante dessa produção discursiva, cabe às pessoas idosas empreenderam um trabalho de constituição de sua subjetividade.

A descrição da subjetividade assumida por idosos será tratada a partir de sequências enunciativas produzidas por sujeitos idosos estudantes na Universidade Aberta à Terceira Idade (UNATI) da Universidade Estadual de Maringá (UEM), a respeito da sua vivência da terceira idade.

\section{A CONSTRUÇÃO DO OBJETO "NOVO IDOSO"}

Assim como Foucault se pergunta quem é o homem, num processo metonímico, é possível indagar-se: quem é o idoso de hoje. A resposta a essa questão é bastante complexa, pois pressupõe que se descreva a subjetividade de idoso assumida por pessoas que vivem nessa faixa etária. Levando-se em conta que a subjetividade é o resultado (ainda que movediço e sempre inacabado) de um processo de subjetivação, trata-se então, de descrever a subjetivação vivida por esses sujeitos.

Esse processo se dá concomitantemente ao processo de objetivação, o que implica considerar que a subjetividade de um novo idoso é construída a partir de uma dispersão de enunciados atravessados por saberes de diversos campos. Essa discursividade pode produzir diferentes subjetividades de idoso e oferecer posições diversas para os sujeitos, a depender das relações estabelecidas social e discursivamente. As pessoas respondem a esses agenciamentos quando assumem ou negam determinadas práticas.

Uma análise discursiva de orientação foucaultiana desenvolve-se pautada na constituição de séries enunciativas e requer que se considere a descrição do enunciado e de sua função no interior dos discursos. De acordo com Foucault (2008, p. 32), "um enunciado é sempre um acontecimento que nem a língua e nem o sentido podem esgotar inteiramente". Isso ocorre porque ele não é uma unidade em si mesmo, mas um cruzamento entre um domínio de estruturas e um jogo de memória, produzindo um efeito de atualidade. Voss e Navarro (2013, p. 97) explicam que "Foucault, no método arqueológico, está interessado no enunciado como acontecimento discursivo: índice paradoxal de novidade e de repetição, na história". Entre os acontecimentos mais recentes em relação à velhice, pode-se destacar a emergência da subjetividade do novo idoso como uma ruptura na história. 
Ponto crucial de uma análise arqueológica, a descrição de um enunciado ocorre a partir da função enunciativa, que compreende as características: referencial, posiçãosujeito, campo associado e existência material. Para Foucault (2008, p.103), o enunciado está ligado a um referencial, que "define as possibilidades de aparecimento e de delimitação do que dá à frase seu sentido, à proposição seu valor de verdade. Dessa forma, o referencial trata-se do objeto construído discursivamente". O segundo elemento da função enunciativa, posição-sujeito, corresponde a uma posição vazia que pode ser ocupada por diferentes indivíduos. A análise discursiva procura, então, "determinar qual é a posição que pode e deve ocupar todo indivíduo para ser seu sujeito." (FOUCAULT, 2008, p. 108). Dessa forma, pressupõe-se sempre o devir que descentra o sujeito. Essa concepção implica assumir, no caso dos idosos participantes, que o discurso produzido por eles sobre si mesmos não é totalmente consciente, nem se origina totalmente neles. Ao contrário, seu dizer e seu agir são fruto da imbricação de diversas práticas e de diversas memórias, as quais muitas vezes eles desconhecem, mas assumem como suas.

O terceiro elemento da função enunciativa, campo associado, permite compreender que a descrição dos saberes e a formação dos objetos não são tomadas como um dado a ser encontrado, mas uma teia a ser descrita a partir das relações entre os enunciados. Foucault (2008) afirma que o enunciado só existe dentro de um campo associativo com outros enunciados, composto de elementos como: a) outras formulações onde o enunciado se inscreve; b) conjunto das formulações a que o enunciado se refere; c) conjunto das formulações que podem vir como consequência do enunciado; d) conjunto das formulações cujo status é compartilhado. Essa série de formulações com as quais o enunciado coexiste atesta sua historicidade, o que permite descrever o trabalho realizado pela memória na sua constituição.

Sendo assim, a posição-sujeito de novo idoso é um lugar construído na função enunciativa que tem o idoso como seu objeto de saber. $\mathrm{O}$ enunciado que descreve e instaura o novo idoso, na mídia, por exemplo, está em relação com: a) enunciados sobre saúde, longevidade, condições de vida etc.; b) outras formulações sobre como eram os idosos de antes e como podem vir a ser os idosos do futuro; c) formulações que discutem o ideal de novo idoso e a forma como ele está sendo vivido, questionam sua veracidade e/ou aplicabilidade, d) outros assuntos que também são tratados em textos da mídia.

Como último elemento da função enunciativa, o enunciado tem uma existência material. Ele precisa de uma superfície, um suporte, um lugar e uma data e, quando essa materialidade se altera, o próprio enunciado também se modifica (FOUCAULT, 2008).

A análise do enunciado deve observá-lo no interior de uma série. Desse modo, a descrição dos modos de relação entre enunciados indica, entre outras coisas, os princípios das práticas que caracterizam um determinado discurso. Sendo assim, as práticas discursivas formam saberes, os quais o método arqueológico permite rastrear. Conforme Araújo (2008, p. 65), "a história dos saberes não deve remeter a algo externo a eles, a algum referente [...]. Trata-se de um outro tipo de história, como já dissemos, pensada para evidenciar a formação dos objetos em um discurso, o que extrapola a simples relação entre dizer e mundo." 
Nesse emaranhado da objetivação de saberes, foi possível transformar as pessoas com mais de sessenta anos em um objeto de saber: o novo idoso. Ao ser tomado como objeto de saber e de análise, o discurso sobre o novo idoso se organiza a partir de uma função enunciativa que propõe um referencial: novas formas de viver a velhice; uma posição-sujeito a ser ocupada por pessoas que possam adotar as práticas necessárias para que a vida seja estendida. Isso se constrói em relação com outros enunciados em que se trata do idoso, da expectativa de vida em diversos lugares e em diversos momentos históricos, das formas de agir e de cuidar do corpo na velhice, entre outros; e também articula superfícies em que isso se materializa, como textos da mídia, textos acadêmicos, depoimentos etc.

Esse processo de objetivação do novo idoso produz inúmeras práticas às quais os idosos devem se submeter para serem considerados novos idosos. Conforme Polla (2013) levantou a partir de enunciados da mídia, o novo idoso é aquele que ocupa diversas atividades, sejam elas de lazer, de estudos, sejam pessoais. Além disso, ele está conectado, acessando e publicando informações on line, o que demonstra o quanto se atualizou e adaptou aos avanços tecnológicos. Por fim, o novo idoso é um sujeito que quer envelhecer sem perder características da juventude como a saúde e a beleza. Mas essa subjetividade não é homogênea:

\footnotetext{
Convivem, na mídia atual, as duas objetivações e subjetivações de idoso: a "nova" e a "velha". Nesse sentido, destaca-se o fato de o Estatuto do Idoso objetivar, na maior parte de seu texto, o "velho" idoso, devido ao fato de ser uma legislação protetiva, que visa a cuidar daqueles idosos com saúde debilitada. Os meios de comunicação, ao contrário, marcam mais a objetivação de "novo" idoso, isto é, aquele que trabalha, faz uso das tecnologias e procura manter-se belo. (POLLA, 2013, p. 99)
}

Também a partir de uma série enunciativa composta por vídeos, fotos e outros enunciados de mídia de textos de mídia, Navarro e Bazza (2012), descrevem as práticas discursivas que contribuem para a subjetivação do novo idoso. Os autores (2012, p. 157) partem de uma visada discursiva que considera que "o sujeito não corresponde a uma individualidade no mundo, as suas enunciações manifestam a presença do exterior na subjetividade. Esse mesmo exterior constitutivo atravessa o idoso, como sujeito no mundo e como referencial das práticas discursivas."

Navarro e Bazza (2012) priorizaram a descrição de discursos que operam na forma de memória e delineiam práticas desejáveis para o novo idoso. A descrição das sequências enunciativas de mídia recortadas apontou as seguintes práticas: a) injunção à saúde e ao cuidar com o corpo; b) injunção ao convívio em grupos, em oposição à solidão e ao convívio apenas com a família; c) injunção à jovialidade em oposição à imagem frágil e de cabelos brancos; d) injunção ao consumo de produtos ou de lazer em oposição ao ato de poupar; e, e) injunção à vivência da sexualidade em vez de sua neutralização.

Essas práticas também são descritas como constitutivas de um ideal de novo idoso por Monteiro e Leite (2011), em análise de material publicitário. As autoras destacam que a representação do corpo velho é construída a partir de um ideal de beleza, longevidade e produtividade. Fatores que os sujeitos devem desenvolver em si para serem considerados pertencentes a essa subjetividade. Esses estudos indiciam uma recorrência na forma de objetivação do novo idoso que, por sua ampla circulação, se instaura na memória discursiva e passa a funcionar como enunciado com o qual o sujeito precisa se haver para elaborar seu processo de constituição do eu, ou seja, sua subjetivação. 
O processo discursivo de constituição de uma subjetividade se dá na imbricação entre as relações de saber-poder, que formam seus objetos, e o processo de subjetivação, que permite aos indivíduos se constituírem como sujeitos de discurso. No caso dos sujeitos idosos, isso significa que o discurso do sujeito idoso sobre si se organiza a partir de relações com as diversas objetivações que as pessoas da terceira idade sofreram. Dessa forma, depois de retomadas as práticas que constituem o objeto de saber novo idoso, inicia-se o levantamento do conceitual da subjetivação foucaultiana, para posterior descrição da subjetivação no discurso do idoso.

Em relação à constituição do eu, no método foucaultiano, sujeito é considerado uma categoria discursiva que não coincide com o sujeito empírico. Fruto do trabalho de construção de saberes, agente e produto de uma rede de poderes, para Foucault (2004a, p. 58),

as posições do sujeito se definem igualmente pela situação que lhe é possível ocupar em relação aos diversos domínios ou grupos de objetos: ele é sujeito que questiona, segundo uma certa grade de interrogações explícitas ou não, e que ouve, segundo um certo programa de informação; é sujeito que observa, segundo um quadro de traços característicos, e que anota, segundo um tipo descritivo.

Nesse sentido, os indivíduos existem empiricamente, mas se tornam sujeitos de um discurso e de uma verdade na medida em que assumem um lugar discursivo. Para se subjetivar pelo discurso de um novo idoso, é preciso que o indivíduo ocupe uma posição no jogo discursivo que instituiu esse objeto, trabalhe com os saberes que foram objetivados ora apropriando-se deles, ora resistindo a eles.

É por isso que o sujeito é também datado, conforme aponta Veyne (2011, p. 179): "o sujeito não é soberano, mas filho de seu tempo; não é possível tornar-se qualquer sujeito em qualquer época. Em compensação, é possível reagir contra os objetos e, graças ao pensamento, tomar distância em relação a eles". Assim, empírica e legalmente cada participante da pesquisa realizada existe e é considerado idoso porque tem mais de 60 anos. Porém, eles se tornam sujeitos idosos na medida em que precisam lidar com aquilo que se produz de verdade sobre os idosos, nos mais variados campos de saber, trabalham sobre memórias, produzem devir e assumem um discurso sobre si mesmos. Esse processo implica entrar na teia das relações de discurso, de práticas e, portanto, de poderes que cercam e constituem a subjetividade do idoso atual.

Se os processos de objetivação constroem um objeto, como é o caso do novo idoso, poder-se-ia acreditar que, ao se fazer uma descrição arqueológica sobre as formas como esse sujeito é representado, demonstrar-se-ia a forma de subjetividade possível para o idoso atual. O processo de constituição da subjetivação, contudo, não coincide com o de objetivação, tendo em vista o que Foucault (1997) nomeou como possibilidade de resistência às estratégias de sujeição. 
Nas sequências enunciativas analisadas na pesquisa, as pessoas são questionadas se são novos idosos e como fazem para ser idosos atualmente. Para responder a isso, eles dialogam com todo um conjunto do que se diz sobre idoso, para delimitar uma posição e um modo de viver para si. As afirmações demonstram que a subjetividade de novo idoso que circula na mídia não é plenamente assumida pelos sujeitos.

Diferentemente de uma tradição intelectual que compreendia o poder como algo que se detém, para Foucault (2005a, p. 35) o poder se exerce; não é atributo de um grupo específico. Não é algo externo ao sujeito do qual ele se apropria, ele circula e organiza as práticas discursivas e, consequentemente, as subjetividades que elas agenciam. Dessa forma, "o indivíduo é um efeito do poder e é, ao mesmo tempo, na mesma medida em que é um efeito seu, seu intermediário: o poder transita pelo indivíduo que ele constituiu". No caso dos idosos, há um jogo de poderes que organiza as práticas e prescreve o que é e como deve agir um idoso na contemporaneidade. Os indivíduos são atravessados por esse poder ora assumindo práticas propostas, ora resistindo a elas.

A capacidade que o poder tem de apreender a todos no jogo de relações estabelecidas não impede manifestações de resistência, o que acaba por estabelecer um jogo de forças que se materializa nos enunciados e os individualiza. De acordo com Foucault (1999, p. 10), “o discurso não é simplesmente aquilo que traduz as lutas ou os sistemas de dominação, mas aquilo por que, pelo que se luta, o poder do qual nos queremos apoderar". Enraizados nas relações sociais, o poder e a resistência a ele classificam os indivíduos atribuindo-lhes uma subjetividade. Pode-se considerar que todos os enunciados (midiáticos, legais, científicos) a respeito do idoso disputam espaço na construção de uma verdade. As práticas de um campo de saber podem se opor às de outro campo. Por exemplo: enquanto pesquisas biológicas tentam definir as características fisiológicas da terceira idade, pesquisas da área de humanas relacionam essa demarcação a questões psicológicas, sociais e econômicas além da fisiológica. Acrescenta-se a isso o fato de que essa subjetividade de idoso é multifacetada, fruto de embates e pode ser aceita, refutada totalmente ou em parte, ressignificada pelos indivíduos com mais de 60 anos.

Nessa perspectiva, subjetivação e subjetividade não estão relacionadas a estados psicológicos, experiências individuais e únicas. Ao contrário. Segundo Fischer (2012), o termo "subjetividade", segundo Foucault, refere-se ao "modo pelo qual o 'sujeito faz a experiência de si mesmo em um jogo de verdade no qual está em relação consigo mesmo"”. Essa relação consigo se dá num jogo de práticas e técnicas por meio das quais o sujeito faz uma experiência de si em um jogo de verdade.

Os modos de objetivação constroem saberes e subjetividades e transformam os seres humanos em sujeitos de um discurso. Contudo, não se trata apenas de uma força que se impõe sobre o sujeito, pois há que se considerar o trabalho dele sobre esses discursos. Fischer (2012, p. 55), ao comentar a teoria foucaultiana, explica que

\footnotetext{
há dois sentidos para a palavra sujeito: sujeito submetido ao outro através do controle e da dependência, e sujeito preso à sua própria identidade, através da consciência ou do conhecimento de si. Em ambos os casos, essa palavra sugere uma forma de poder que subjuga e assujeita.
} 
A visão de um sujeito que trabalha sobre si, paralelamente à concepção do sujeito que é constituído pelas práticas discursivas, desenvolve-se principalmente a partir dos trabalhos a respeito da estética da existência. Nessa perspectiva, Foucault (2003, p. 75) postula que

\begin{abstract}
no decurso de sua história, os homens jamais deixaram de construir a si mesmos, isto é, de deslocar sua subjetividade, de constituir para si uma série infinita e múltipla, de subjetividades diferentes e que jamais terão fim e jamais nos colocarão diante de algo que seria o homem.
\end{abstract}

Nos estudos sobre a estética da existência, as análises de Foucault (2005b) perseguem a relação entre a verdade e o sujeito, a partir de uma visada genealógica, em que, para refletir sobre essa questão do presente, analisa-se esse problema em outras camadas históricas. Para tanto, o autor recua à questão dos prazeres sexuais e do cuidado de si (epiméleia heautoû) na antiguidade greco-romana. O objetivo de tal recorte é o de compreender como emerge e se constitui a subjetividade moral dos indivíduos a partir de uma cultura de si.

Foucault procura a verdade sobre o sujeito a partir da articulação entre subjetividade e verdade pelo viés histórico. Candiotto (2008, p. 88) aponta as questões que se originam desse posicionamento:

\footnotetext{
que relação o sujeito estabelece consigo a partir de verdades que culturalmente lhe são atribuídas? Tal interrogante parte do fato de que em qualquer cultura há enunciações sobre o sujeito que, independentemente de seus valores de verdade, funcionam, são admitidas e circulam como se fossem verdadeiras.
}

Esse encaminhamento possibilita saber quais são os efeitos de subjetivação a partir da existência de discursos que pretendem dizer uma verdade para o sujeito. Assumindo também essa perspectiva genealógica, o questionamento sobre o que o idoso atual faz de si foi pensado a partir da forma como o aluno da UNATI se discursiviza em relação às formas de sua objetivação.

Ao explicar a proposta foucaultiana de compreensão da subjetividade, Gros (2011, p. 461) pontua que seria possível "um sujeito verdadeiro, não mais no sentido de uma sujeição, mas de uma subjetivação". As técnicas de si seriam formas de o indivíduo tornar-se sujeito e objeto para si próprio e resistir às técnicas de dominação (poder) e às técnicas discursivas (saber). O autor (2011, p. 475) explica que "o indivíduo-sujeito emerge tão-somente no cruzamento entre uma técnica de dominação e uma técnica de si. Ele é a dobra dos processos de subjetivação sobre os procedimentos de sujeição, segundo duplicações, ao sabor da história, que mais ou menos se recobrem."

Por outro lado, esses processos contemplam um trabalho do sujeito que reelabora essas práticas de sujeição e abrem, portanto, um espaço de liberdade. Essa visada abre caminhos para o estudo das subjetividades contemporâneas: uma das vias para compreender os processos de subjetivação é analisar, paralelamente às relações de sujeição, o trabalho cotidiano, ordinário do discurso. Em relação ao idoso atual, significa que discursos políticos, midiáticos e de demais esferas institucionalizadas objetivam 
quem é o idoso hoje. Essa objetivação construiu uma imagem, recorrentemente denominada novo idoso, composta não só pela forma como o sujeito é visto, mas pelas práticas que o indivíduo deve adotar para ser daquela forma. Ao mesmo tempo em que ocorre esse processo de sujeição, há um microprocesso (e também um micropoder) em ação, por meio do qual as pessoas ditas idosas atuam cuidando de si mesmas em prol de uma vida mais prazerosa. Isso implica assumir ou rejeitar as práticas apresentadas como típicas do novo idoso, conforme suas necessidades e possibilidades. Trata-se, portanto, da subjetivação. Cabe, então, questionar qual seria o estatuto da velhice hoje e qual estatuto pode vir a emergir a partir das práticas atuais, com todos os jogos de saberes e poderes que o compõem.

\section{A SUBJETIVAÇÃO DO IDOSO ESTUDANTE DA UNATI-UEM}

As sequências enunciativas que serão analisadas neste trabalho fazem parte de uma série enunciativa maior que foi composta para nossa pesquisa de doutoramento. Para tratar de questões de subjetivação do idoso atual, foram considerados os sujeitos em situação de estudos na UNATI-UEM, que é um projeto que visa a oferecer ensino não formal a idosos. Constituído como um órgão da universidade, a UNATI oferece cursos, ministrados por professores da instituição, voltados aos interesses dessa faixa etária. Não se trata de uma graduação da qual o aluno recebe um diploma, mas de cursos independentes dos quais os estudantes recebem um certificado.

A construção da série enunciativa contemplou produções de dois gêneros diferentes: relatos e entrevistas, ambos tratando das formas de esses sujeitos viverem a terceira idade. Para a produção do relato, os alunos tiveram aulas sobre esse gênero e, em seguida, foi-lhes solicitado que escrevessem um relato contando sobre sua rotina e sua experiência de vida no atual momento. Para a produção das entrevistas, foram feitas questões sobre sua rotina de vida, opinião dos entrevistados sobre o novo idoso e sobre a $\mathrm{UNATI}^{2}$.

Uma das perguntas questionava se eles se consideram novos idosos e por quê. Entre as práticas em que os idosos se reconhecem como "novo idoso", destaca-se a questão do humor. Em enunciados como:

\footnotetext{
S4 - "Eu sou muito divertida. Gosto de diversão" ou "Eu ando de bicicleta com os netos" S9 - "Eu sou muito divertida".
}

Esses sujeitos atribuem a si a subjetividade de novos idosos por acreditarem ser bem-humorados. Isso demonstra que o bom humor figura como uma das práticas que supostamente compõe o discurso sobre o novo idoso, e faz parte do discurso que eles assumiram sobre si mesmos.

\footnotetext{
${ }^{2}$ Quando transcritos trechos de relatos, eles são introduzidos pela letra R. Nas sequências retiradas das entrevistas, as falas da pesquisadora são identificadas pela letra $\mathrm{E}$ e as respostas dos idosos introduzidas pela letra S. Para preservar a identidade dos participantes, em vez de seus nomes, são apresentados números que identificam cada informante.
} 
A ideia da diversão retoma uma memória historicamente associada a representações de idosos: o sujeito cordial e o ranzinza. Ser divertido está no campo da cordialidade, porém desloca o seu sentido, pois a cordialidade muitas vezes tinha relação com a figura maternal/paternal que avós assumiam. Ser divertido, contudo, desloca o campo da condescendência, tendo em vista que implica as relações não só com familiares, mas com as pessoas encontradas em novos lugares de interação. Enquanto a cordialidade relacionase a uma posição fruto da maturidade, ser divertido parece estar associado à jovialidade, o que poderia ser indício das práticas descritas como juvenilização dos idosos (cf. COUTO; MEYER, 2011).

As características e as atitudes pressupostas para os idosos mudam ao longo do tempo, prova de que são construídas historicamente. Ao assumir essa característica como componente de sua subjetividade, esse indivíduo constrói-se como sujeito histórico dessas práticas. Ao mesmo tempo em que se volta para si para se constituir, suas escolhas e seu trabalho sobre si mesmo suportam e apontam uma densidade histórica.

Outro aspecto em que a imagem que o sujeito tem de si e a imagem de um novo idoso coincidem é a necessidade de atividade, seja ela social, física ou psíquica. Esse discurso se materializa em afirmações como

\footnotetext{
S4 - [...] hoje em dia eu sou muito elétrica, então eu não tenho pensamento ruim. Eu falo: "Vou em tal lugar" e eu vou.

S10 - Acho [que sou uma nova idosa], eu acho. Eu acho que o idoso de uns anos atrás não fazia o que a gente faz hoje.
}

A atividade figura como um dos elementos que compõem, no imaginário social, a subjetividade de novo idoso. Ocorre, contudo, uma particularidade em relação à percepção das atividades: em comparação às possibilidades de atividades de que dispunham os idosos da geração anterior, por exemplo, esses sujeitos consideram-se mais ativos em função das possibilidades de que dipõem:

\section{E - Se eu te perguntasse se você acha que você é uma nova idosa, você acha? \\ S8 - Sim, pela oportunidade que eu estou tendo agora.}

Afirmações como essa indicam uma percepção de que a nova forma de viver tem a ver com mudança nas condições concretas de sua existência, o que reforça as teorias que compreendem a terceira idade atual como experiência de uma geração específica (cf. SILVA, 2008). Essa percepção da mudança é indício de como a memória atua na construção dos sentidos. O enunciado em que se afirma que o novo idoso é ativo é povoado por outros enunciados que o margeiam. Fazem parte do campo associado desse enunciado outros enunciados que, antes, afirmavam a necessidade do repouso e da reclusão. A ruptura nesse enunciado coloca o idoso atual em outra posição de sujeito: permite-lhe ocupar outros espaços, ao mesmo tempo em que lhe impõe isso. Levar uma vida ativa é uma prática que se materializa também nos relatos: 
R3 - Minha vida atual não trouxe grandes mudanças, visto que estou com 61 anos, e continuo na ativa $[\ldots]$.

R8 - Estou com 72 anos, mas continuo dinâmica como nos tempos da minha mocidade.

R5 - [...] ]eu levo a vida normal como-se não fosse idoso.

A noção de atividade sofre um acúmulo, na medida em que é relacionada à distinção entre normal/anormal. São os saberes, disseminados pela sociedade e assumidos como verdade, que vão construir a ideia de que somente na juventude se tem as condições de mobilidade, saúde, etc. que possibilitam ser ativo.

Nesse caso, porém, opera-se uma ruptura na percepção da atividade: ela não é mais vista como uma forma de ser idoso diferente de seus antepassados, mas uma maneira de estender as atividades de sua vida adulta. A atividade implica uma noção de continuidade da fase adulta. Como uma fase de entremeio, o processo de subjetivação da pessoa da terceira idade manifesta-se constituído na tensão desse pêndulo que ora aponta para a fase adulta, ora aponta para a velhice. Ser idoso hoje é estar na contradição entre esses dois papéis que, historicamente são mais demarcados. Mas ao afirmar ser normal por manterse ativo, esse sujeito indica uma posição-sujeito que foi construída no discurso contemporâneo e que ele assumiu para si.

Também se observa a subjetivação como novo idoso a partir de um processo de degeneração mais lento.

S10 - "Um homem, quando ele chegava aos sessenta anos era um velho acabado. Hoje não, aos oitenta está inteiro".

Esse alongamento da juventude parece ser assumido também pelos entrevistados. Alguns deles chegam até a elencar motivos para que hoje eles demorem mais para envelhecer:

S5 - Antigamente as pessoas achavam que com cinquenta anos já era velho, considerada velha. E eu acho que a mulher não se impunha. Essas ginásticas, os cosméticos, o cuidado com a pele... Eu acho melhora a autoestima da mulher e ela está mais valorizada também.

A prática de manutenção da juventude é assumida pelos idosos tanto em relação a aspectos físicos quanto psíquicos. Tal prática está amparada em um investimento de poder que estuda, esquadrinha e governa o corpo. Isso possibilitou a disseminação das ginásticas, dos cosméticos, citados pela idosa, e de outros cuidados que ciências como a medicina, a fisioterapia, a psicologia, entre outras, prescrevem para conservar o corpo do idoso como jovem, ou ao menos retardar sua constituição em um corpo velho. Na sequência enunciativa:

\footnotetext{
S7 - Eu sou [novo idoso], eu tenho idade, mas eu não sou velho. Minha cabeça não é cabeça de velho. [...] Então, mas eu não tenho cabeça de velho. E, me adaptar às coisa de hoje, eu sou fácil de adaptar",
} 
há indícios de que a idade cronológica não coincide com a imagem que o sujeito faz de si e uma das coisas que garante isso é a sua capacidade de adaptação, característica atribuída ao novo idoso e à qual ele se associa.

A possibilidade de estudar é um dos fatores que fazem com que os idosos na UNATI se identifiquem com essa subjetividade. Diante do questionamento sobre se considerar um novo idoso, algumas respostas positivas têm relação com o fato de estudar nesse momento da vida:

S8 - Sim, pela oportunidade que eu estou tendo agora.

S5 - "Eu acho que a gente investiu. A gente foi investindo, estudando mais.",

R4 - Bem, agora posso fazer tudo o que mais gosto, e também a oportunidade de novas amizades. Aí descobri essa beleza da UNATI que dá a oportunidade de realizarmos um sonho do passado. Frequentarmos uma universidade.

Atuando como um dispositivo de saber-poder, a UNATI faz falar e faz viver a partir de uma nova posição-sujeito, segundo a qual estudar configura-se como uma resposta à injunção por atualização, por atividade e por relações sociais:

R3 - O que me levou a concorrer a uma vaga na UNATI, foi justamente para ver provar da minha idade ou mais velhos que eu tentando sair da sua rotina, manter a mente aberta, aprender o que não teve oportunidade de aprender antes, por faltar tempo ou mesmo oportunidade.

Nesse sentido, frequentar a UNATI representa uma nova forma de ser. É uma maneira de se manter ativo e fazer amizade, como consequência do alongamento da fase adulta. As práticas comuns ao novo idoso emergem, portanto, em uma teia de condições sociais e históricas que possibilitaram uma nova forma de viver depois dos sessenta anos e, ao mesmo tempo, impelem os indivíduos a assumir essa posição de sujeito.

Entre as práticas assumidas pelos idosos como características de novo idoso, figuram ações relacionadas à tecnologia:

R1 - Depois almoço e vou ver o meu facebook. Jogo paciência [...] Estas são as atividades do meu dia-a-dia. Também faço crochê, tricô e bordado com agulha mágica e agulha russa.

R10 - Comprei um computador gosto muito de jogos, isso me distrai bastante.

A prática considerada nova divide espaço com práticas tradicionalmente atribuídas a essa faixa etária. Ações como conversar e saber notícias de amigos e parentes assim como jogar para passar o tempo são mantidas no cotidiano dessas pessoas, porém, agora, mediadas por um novo suporte: o computador. Conforme afirma Foucault (1999, p, 26), "o novo não está no que é dito, mas no acontecimento de sua volta". Nesse caso, o novo está na volta ou na permanência de um conjunto de ações e nele mesmo apresenta-se a ruptura, por meio da qual o sujeito incorpora, em seu dia a dia, inovações tecnológicas.

As considerações dos idosos sobre o que eles tinham de novo idoso trouxeram em seu bojo também os elementos que compõem essa subjetividade na compreensão desses 
indivíduos. A regularidade de suas respostas apontou a formulação de um enunciado segundo o qual "o idoso deve ser ativo". Esse enunciado se sustenta em um regime de verdade construído historicamente por saberes de diversos campos, entre eles a própria gerontologia, que defende a tese da velhice ativa. Por ser embasada teoricamente também na gerontologia, a UNATI funciona sob esse regime de verdade, pois é desenvolvida para idosos ativos e incentiva os que lá estão a serem assim. Tal verdade também circula na mídia, na medida em que são representadas predominantemente figuras idosas ativas em novelas, propagandas, reportagens etc. Dessa forma, a mídia, a gerontologia e a própria UNATI funcionam como dispositivos a partir dos quais são construídos saberes, relações de poder e modos de viver aplicáveis ao novo idoso.

Esse regime é constituído a partir de práticas discursivas que estabelecem como deve ser e/ou agir um novo idoso. As sequências enunciativas recortadas apontam para três elementos sobre os quais essas práticas incidem: o conhecimento, os hábitos e as crenças. Em relação ao conhecimento, a prática que constitui o novo idoso é materializada pelo verbo 'estudar'. Tal ação é assumida pelos sujeitos entrevistados, visto que todos eles frequentam a UNATI. Em relação aos hábitos considerados do novo idoso e assumidos por esses sujeitos, observa-se a adaptação ao uso da tecnologia. Faz parte, portanto, da rotina de ser ativo a prática de estar atualizado sobre as estratégias modernas, materializado pelas expressões: computador e elementos do mundo virtual, como facebook. As crenças, contudo, funcionam como o lugar em que se opera a resistência e o sujeito não se reconhece como um novo idoso.

Há momentos em que os entrevistados não se consideram novos idosos, ou seja, não percebem semelhança entre a sua forma de viver a terceira idade e as injunções descritas como próprias ao novo idoso. Uma delas é o imperativo da adaptação às novidades quando relacionada a crenças. A afirmação:

S1 - "Olha, tem muita coisa que continua tudo velho, viu? Algumas coisas... Mas eu me considero uma pessoa que aceita muito as mudanças"

aponta um distanciamento das práticas de novo idoso em prol de algumas questões em que o sujeito percebe não ter mudado e considera-se portanto um "velho idoso". Essa contradição entre o novo e o velho fica situada no fato de aceitar ou não as mudanças. No decorrer desta entrevista, a idosa relata a aceitação das mudanças de seu corpo, em contraposição a uma dificuldade em aceitar formas de viver o casamento (casamento aberto e divórcio) e a sexualidade (homossexualidade) de maneiras diferentes da que lhe foi ensinada e por ela adotada.

Essa compreensão de si mesma é um indício de que existe uma produção discursiva que constrói uma subjetividade de novo idoso aceita como verdadeira, e para se considerar nova idosa, essa mulher acredita ser necessário ter a mentalidade e investir em práticas consideradas modernas e atuais. Estar aberto a mudanças faz parte do imaginário sobre o que é ser novo idoso, atualmente. Na série enunciativa analisada, algumas dessas mudanças são aceitas, como o uso da tecnologia e a maleabilidade para aceitar as mudanças do corpo. Essa prática, contudo, não é adotada total e genericamente. Sobre as questões consideradas novas, esses sujeitos projetam suas crenças, as regras de formação 
às quais estão acostumados por se submeterem a elas por longo tempo. Isso constitui um crivo pelo qual passam as mudanças a serem aceitas e adotadas por esse idoso. Diante da injunção para assumir as verdades deste momento, o sujeito se vê em uma relação de tensão, posto que resiste a algumas práticas que constituem esse discurso construído.

Outro aspecto que justifica uma não coincidência entre o novo idoso e os idosos da UNATI-UEM se refere às atividades de lazer. Estudos, reportagens e pesquisas (cf. MORAES, 2011) demonstram a prática da dança em bailes como algo que caracteriza a rotina dos idosos, porém esses sujeitos não as reconhecem como suas:

S3 - "Porque da mídia, eles mostram o novo idoso dançando. A gente sai e eu acho engraçado, porque a turma da professora Terezinha, a gente estava comentando que ninguém vai em baile, ninguém dança. Eles dizem "Nossa, esses velhos da televisão não têm nada a ver com a gente.

Conforme a própria idosa explica, é comum ver reportagens que mostram o novo idoso como um frequentador de bailes, contudo, entre os idosos estudantes da UNATI, tal prática não se manifesta. Apesar de os bailes de idosos serem atividades promovidas há bastante tempo para socialização, recentemente essa se transformou em uma atividade que parece caracterizar as atividades sociais do novo idoso.

A instituição oferece um número reduzido de vagas - perto de 300 - e sempre há fila de espera, por isso estar matriculado ali significa já pertencer a um grupo privilegiado. Os idosos dali resistem a uma prática de interação social comum à maioria dos idosos em prol de outras atividades. Enquanto entidades assistenciais promovem bailes e passeios, a UNATI-UEM possibilita a interação mediada pelo contexto educacional, por meio de aulas mais teóricas em que são utilizadas salas de aula; aulas mais práticas, como as de informática, sapateado, canto, natação, etc.; e também por meio de grupos que treinam esportes, como handebol. Os passeios propostos pela instituição são voltados à participação em congressos ou são viagens de estudo, diferentemente de passeios que só visam à recreação. Dessa forma, a subjetividade de novo idoso pode ser considerada fruto do olhar do poder, via dispositivos como a mídia, a pesquisa científica e a própria UNATI. Porém, sobre ela é lançado o olhar do sujeito que tensiona a densidade histórica que compõe os modelos de que se serve e os seus anseios mais particulares.

Um dos fatores que distanciam as práticas dos sujeitos às do chamado novo idoso é a questão financeira, considerando o custo que esta forma de viver acarreta. Ao ser questionado se havia coisas do novo idoso com as quais não se identificava, o sujeito respondeu:

S7 - Tem né, o poder aquisitivo. Às vezes eu tenho até vontade de dar um passeio, fazer uma turnê pela Europa, mas eu não consegui ainda ir”.

Observa-se, porém, que apesar de afirmar não ter condições de viajar, o sujeito está afetado por esse desejo e afirma já ter feito passeios e cruzeiro, na verdade, o que lhe falta seriam passeios mais dispendiosos que aqueles que já fez. Dessa forma, apesar de afirmar não se identificar com essa prática, já está afetado por ela. 
Nas práticas discursivas midiáticas há um tipo de idoso para o qual são endereçados os discursos. A venda de viagens e cruzeiros, planos de saúde completos, financiamento em bancos, tratamentos estéticos e de saúde, entre outros produtos, visam a um sujeito que dispõe de recursos para custeá-los e de informação para buscá-los. Assumir tal posição discursiva requer condições de existência bastante privilegiadas, consequentemente, acessíveis a um grupo restrito. Por circular na mídia e atingir um grande percentual das pessoas com mais de sessenta anos, muitos idosos se sentem impelidos a entrar nessa ordem de discurso e assumir tal posição. Isso faz com que surjam posições de sujeito como a do entrevistado: interpelado pela subjetividade ofertada e sem as condições concretas para exercê-la. Contrariamente à ideia de uma identidade para os idosos na História, trata-se de um exemplo da dispersão em meio à qual se constituem as subjetividades idosas possíveis na atualidade.

Além de não se reconhecerem como novo idoso baseados em coisas que eles acreditam não fazer, há momentos em que os sujeitos não se descrevem como novo idoso por se identificarem com práticas de seus pais e avós, os supostos velhos idosos:

S3 - Comparando minha mãe e eu, eu acho que não tem muita diferença, na minha família, os idosos já eram mais ativos, porque a minha mãe sempre viajou, meu pai gostava de viajar, e gostava de festa.

A partir desse recorte, pode-se observar que, no percurso de cada sujeito, identificar-se à classificação de novo idoso não depende somente de conhecer e assumir as práticas descritas como próprias a ele, mas também de isso ter sido assumido recentemente, como emblema da mudança. Se a prática já existia na vida da pessoa, o que ocorre em seu discurso é um descrédito à existência dessa subjetividade:

\footnotetext{
S6 - Eu acho que não [sou um novo idoso], porque eu sei lá... A gente tem que ser aquilo que o idoso é, né? Não adianta ter oitenta anos e querer ter sessenta.

$\mathrm{E}-\mathrm{O}$ senhor acha que existe esse novo idoso?

S6 - Sei lá, acho que é muita propaganda.
}

O sujeito não se discursiviza como novo idoso. Por ter 84 anos no período da entrevista, parece atribuir a subjetividade de novo idoso àqueles que estão mais próximos dos 60. Parte de um domínio associado de memória, essa fala remete à teoria de que a terceira idade seria uma fase entre a vida adulta e a velhice. Desse modo, em sua idade, ele já faria parte da chamada velhice. O funcionamento do poder, com todos os micropoderes que o constituem, estipula formas de vida, classifica, rotula. Com isso cria imagens de subjetividades, como a do novo idoso, na qual o sujeito da pesquisa não se reconhece.

Apesar de não se incluir na chamada terceira idade, opina sobre ela: parece desconfiar da existência de um novo idoso tal como observa a mídia descrever. As respostas dadas a essa questão podem ser consideradas indícios de que a compreensão do que sejam as práticas do novo idoso não é homogênea, assim como a ocorrência dessas práticas na rotina dos idosos é variável. Desse modo, não é possível fazer uma afirmação categórica sobre a subjetivação dos idosos da UNATI como novos idosos assumidos ou como pessoas que rejeitem tal caracterização. O que se verifica é um trabalho particular 
de construção da sua existência a partir do que lhe é oferecido em termos de condições concretas de existência (biótipo, saúde, condições financeiras) atravessado pelas condições discursivas peculiares a esses sujeitos.

\section{CONSIDERAÇÕES FINAIS}

Para colocar em questão a subjetividade de idoso possível na atualidade, partiu-se da concepção foucaultiana de que subjetivar-se é processo nunca acabado, que imbrica o trabalho discursivo de objetivação dos saberes e o trabalho do sujeito de constituição do eu, em meio a essa teia. Objetivação e subjetivação se dão atravessadas pela densidade histórica dos saberes e pelas relações de poder que orientam as práticas discursivas.

As pessoas com mais de sessenta anos subjetivam-se como idosos na atualidade a partir de uma consideração da produção discursiva que objetiva o chamado novo idoso. Ser sujeito dessas práticas implicaria ser jovial, se atualizar e ser ativo profissionalmente, intelectualmente, socialmente, sexualmente etc. Diante das coerções para assumir essa posição-sujeito, as pessoas idosas exercem o seu micropoder no cotidiano ao constituírem-se de modo a se colocar nesse dispositivo da terceira idade, mas resistir a ele a partir de alguns deslocamentos.

Em relação à subjetividade assumida pelos idosos, observa-se um processo de identificação a práticas como o exercício da jovialidade, a disposição para se atualizar e aceitar as mudanças da sociedade e a tentativa de se manter ativo em diversas áreas. Em contrapartida, há pontos de resistência: as crenças e a opção por determinadas atividades de lazer são pontos em que os sujeitos deslizam e se constituem a partir de práticas consideradas mais tradicionais. Configura-se, portanto, uma subjetividade de idoso atual, considerando a investigação realizada, que materializa a contradição entre um novo idoso - imposto pela contemporaneidade - que ele está se tornando e um velho idoso, que ele ainda não deixou totalmente de ser.

\section{REFERÊNCIAS}

ARAÚJO, I. L. Foucault e a crítica do sujeito. 2. ed. Curitiba: Ed. da UFPR, 2008.

CANDIOTTO, C. Subjetividade e verdade no último Foucault. Trans/Form/Ação. São Paulo, v. 31 n. 1, p. 87-103, 2008.

COUTO, E. S.; MEYER, D. E. Viver para ser velho? Cuidado de si, envelhecimento e juvenilização. Revista FACED, Salvador, n. 19, p. 21-32, jan./jun. 201.

FISCHER, R. M. B. Trabalhar com Foucault: arqueologia de uma paixão. Belo Horizonte: Autêntica, 2012.

FOUCAULT, M. Vigiar e punir. Petrópolis: Vozes, 1997. . A ordem do discurso. 5. ed. São Paulo: Ed. Loyola, 1999. . A vida dos homens infames. In: Foucault, M. Estratégia poder-saber. Ditos e Escritos IV. Rio de Janeiro: Forense Universitária, 2003. $2005 \mathrm{a}$. . Em defesa da sociedade: curso no Collège de France (1975-1976). São Paulo: Martins Fontes, História da Sexualidade III. Rio de Janeiro, Graal, 2005b. A arqueologia do saber. 7. ed. Rio de Janeiro: Forense Universitária, 2008. 
GROS, F. Situação do curso. In: FOUCAULT, M. A hermenêutica do sujeito. 3. ed. São Paulo: Martins Fontes, 2011, p. 456- 493 .

MORAES, A. O corpo no tempo: velhos envelhecimentos. In: DEL PRIORE, M.; AMANTINO. M. (Org.). História do Corpo no Brasil. São Paulo: Unesp, 2011. p. 427-452.

MONTEIRO, E.; LEITE, Baracuhy M. R.. Sexo, saúde e esporte: Os discursos da mídia sobre o corpo velho. In: SIMPÓSIO INTERNACIONAL DE ESTUDOS DE GÊNEROS TEXTUAIS, 6., 2011. Anais... Natal: Universidade Federal do Rio Grande do Norte, 2011.

NAVARRO, P.; BAZZA, A. B. A subjetivação do "novo idoso" em textos da mídia. Estudos da Língua(gem), Vitória da Conquista, v. 10. n. 2, p. 143-159, dez. 2012.

POLLA, D. Objetivação e subjetivação do sujeito idoso pelas lentes da mídia contemporânea. Maringá, 2013. Dissertação de Mestrado. Disponível em: <http://www.ple.uem.br/defesas/def_daniela_polla.htm>. Acesso em: 15/03/2016.

SILVA, L. R. F. Terceira Idade: nova identidade, reinvenção da velhice ou experiência geracional? Phisis: Revista de Saúde Coletiva, Rio de Janeiro, v.18, n. 4, p. 801-815, 2008.

VEYNE, P. Foucault: seu pensamento, sua pessoa. Rio de Janeiro: Civilização Brasileira, 2011. VOSS, J.; NAVARRO, P. A noção de enunciado reitor de Michel Foucault e a análise de objetos discursivos midiáticos. Linguagem em (Dis)curso, Tubarão, v. 13, n. 1, p. 95-116, jan./abr. 2013.

Recebido em: 28/03/16. Aprovado em: 22/09/16.

Title: The constitution of subjectivy in elderly discourse about himself/herself Author: Adélli Bortolon Bazza

Abstract: In this study, it was proposed to analyze the subjectivation of the elderly in the Universidade Aberta à Terceira Idade (UNATI), of the Universidade Estadual de Maringá (UEM). While some papers approach the discourse about the elderly, here it is proposed to analyze the practices that compose a discourse of the elderly about himself/herself. Based on a discursive perspective and grounded on Michel Foucault's thoughts, this study aims at describing the process of subjectivation of the UNATI-UEM student, parting from the subjection-subjectivation opposition. The enunciate series analyzed was comprised of ten semi-structured interviews conducted with UNATI-UEM students and of twelve reports produced by them. The analysis pointed that the researched subjects establish resistance to the new elderly ideal, inasmuch as they adopt a few of the practices which compose this subjectivity while rejecting others.

Keywords: Subjetictivity. Elderly. Discourse.

Título: La constitución de la subjetividad en el discurso del mayor sobre si mismo Autor: Addéli Bortolon Bazza

Resumen: En esta investigación fue propuesto analizar la subjetivación del mayor en contexto de enseñanza en la Universidade Aberta à Terceira Idade (UNATI), de la Universidade Estadual de Maringá (UEM). Mientras algunos trabajos abordan el discurso sobre el mayor, se propone analizar las prácticas que componen un discurso del mayor sobre él mismo. Anclada en perspectiva discursiva en el pensamiento de Michel Foucault, fue objetivado describir el proceso de subjetivación del estudiante da UNATI-UEM, desde la oposición sujeción-subjetivación. La serie enunciativa analizada fue compuesta por diez entrevistas semiestructuradas hechas con estudiantes de la UNATI-UEM y de doce relatos producidos por ellos. El análisis apuntó que los sujetos participantes investigados establecen resistencia al ideal de nuevo mayor, en la medida en que adoptan algunas de las prácticas que componen esa subjetividad, mientras rechazan otras.

Palabras-clave: Subjetividad. Mayor. Discurso.
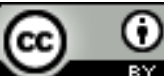

Este texto está licenciado com uma Licença Creative Commons Atribuição 4.0 Internacional. 